\title{
Time course and progression of wild type a-Synuclein accumulation in a transgenic mouse model
}

David Amschll ${ }^{1 \dagger}$, Jörg Neddens ${ }^{1 \dagger}$, Daniel Havas ${ }^{1}$, Stefanie Flunkert ${ }^{1}$, Roland Rabl ${ }^{1}$, Heinrich Römer ${ }^{2}$, Edward Rockenstein ${ }^{3}$, Eliezer Masliah ${ }^{3}$, Manfred Windisch $^{1}$ and Birgit Hutter-Paier ${ }^{1 *}$

\begin{abstract}
Background: Progressive accumulation of a-synuclein (a-Syn) protein in different brain regions is a hallmark of synucleinopathic diseases, such as Parkinson's disease, dementia with Lewy bodies and multiple system atrophy. aSyn transgenic mouse models have been developed to investigate the effects of a-Syn accumulation on behavioral deficits and neuropathology. However, the onset and progression of pathology in a-Syn transgenic mice have not been fully characterized. For this purpose we investigated the time course of behavioral deficits and neuropathology in PDGF- $\beta$ human wild type $a-S y n$ transgenic mice (D-Line) between 3 and 12 months of age.

Results: These mice showed progressive impairment of motor coordination of the limbs that resulted in significant differences compared to non-transgenic littermates at 9 and 12 months of age. Biochemical and immunohistological analyses revealed constantly increasing levels of human a-Syn in different brain areas. Human a-Syn was expressed particularly in somata and neurites of a subset of neocortical and limbic system neurons. Most of these neurons showed immunoreactivity for phosphorylated human a-Syn confined to nuclei and perinuclear cytoplasm. Analyses of the phenotype of a-Syn expressing cells revealed strong expression in dopaminergic olfactory bulb neurons, subsets of GABAergic interneurons and glutamatergic principal cells throughout the telencephalon. We also found human a-Syn expression in immature neurons of both the ventricular zone and the rostral migratory stream, but not in the dentate gyrus.
\end{abstract}

Conclusion: The present study demonstrates that the PDGF- $\beta$ a-Syn transgenic mouse model presents with early and progressive accumulation of human a-Syn that is accompanied by motor deficits. This information is essential for the design of therapeutical studies of synucleinopathies.

Keywords: Behavior, Immunofluorescence, Motor deficit, Mouse model, Parkinson's disease, Phosphorylation, Synucleinopathy, a-Synuclein, Transgene

\section{Background}

Synucleinopathic diseases, like Parkinson's disease (PD), dementia with Lewy bodies (DLB) and multiple system atrophy (MSA), are all characterized by a pathologic aggregation of $\alpha$-Synuclein ( $\alpha$-Syn) protein in distinct brain regions (reviewed by [1]). Increased expression of $\alpha$-Syn can be caused by a dominant heritable form of PD due to duplication or triplication of the $\alpha$-Syn gene [2-4]. In

\footnotetext{
*Correspondence: birgit.hutter-paier@qps.com

${ }^{\dagger}$ Equal contributors

'QPS Austria GmbH, Parkring 12, Grambach 8074, Austria

Full list of author information is available at the end of the article
}

order to model such synucleinopathies in vivo different mouse models were developed that overexpress human wild type $\alpha$-Syn (h $\alpha$-Syn) [5-12]. When expression is driven by the murine Thy 1 promoter, transgenic mice accumulate wild type ho-Syn in cortical and subcortical regions including the nigrostriatal system $[6,13]$ whereas under the human PDGF- $\beta$ promoter h $\alpha$-Syn accumulates preferentially in the neocortex and limbic system (D-Line) [5].

Abnormal accumulation of ho-Syn in D-Line transgenic mice is accompanied by alterations in mGluR5 and autophagy similar to what has been observed in

\section{Biomed Central}

(c) 2013 Amschl et al.; licensee BioMed Central Ltd. This is an Open Access article distributed under the terms of the Creative Commons Attribution License (http://creativecommons.org/licenses/by/2.0), which permits unrestricted use, distribution, and reproduction in any medium, provided the original work is properly cited. 
patients with dementia with Lewy bodies $[14,15]$. Moreover the behavioral and neurodegenerative pathology in D-Line mice can be reversed with mGluR5 antagonists [15] or by promoting the clearance of $\alpha$-Syn with rapamycin [14], Beclin 1 [16,17] and neurosin [18]. Given the behavioral phenotype and the predominant accumulation of $\alpha$-Syn in the neocortex and limbic system, these studies suggest that the PDGF- $\beta$ h $\alpha$-Syn transgenic mouse model reproduces some aspects of synucleinopathies such as DLB. Recent studies have tested compounds developed to ameliorate PD-like pathology in the D-Line mouse model and were able to show a reduction in the accumulation of $\alpha$-Syn, total and oxidized $\alpha$-Syn levels and behavioral deficits [19-22].

Taken together, these results indicate that this transgenic model might be useful for studies of $\alpha$-Syn target validation. However, the progression of the behavioral deficits and pathology in D-Line mice has not been fully characterized. For this purpose we investigated the time course of behavioral deficits and neuropathology in DLine mice. The occurrence of motor deficits was investigated using a challenging beam walk paradigm. We also quantified ho-Syn expression in the hippocampus and striatum using a biochemical approach. Moreover, by quantitative immunofluorescence at different ages we compared expression levels of both murine $\alpha$-Syn and ho-Syn in the cortex, hippocampus, striatum and substantia nigra relative to non-transgenic littermates. Furthermore, we identified several cell populations that express transgenic ho-Syn in different areas of the adult brain.

\section{Results}

\section{Progressive motor deficits of D-Line mice}

Motor coordination, in particular of the hind limbs, and balance of all mice was evaluated with the challenging beam walk test at 6,9 and 12 months of age to evaluate progression of motor deficits in adult, mature and aging mice. The time to cross the beam, the number of steps and slips, and the ratio of slips per step was recorded. No significant changes in the number of slips were observed in 6 months old D-Line and control animals (Figure 1A). 9 months old transgenic and non-transgenic male mice made significantly more slips compared to the corresponding female mice (Figure 1B). Transgenic female mice of the same age performed significantly worse compared to the corresponding female non-transgenic controls as analyzed by t-test. The same trend was observed in male mice, but the results were not statistically significant (Figure 1B). The observed deficits faded at the age of
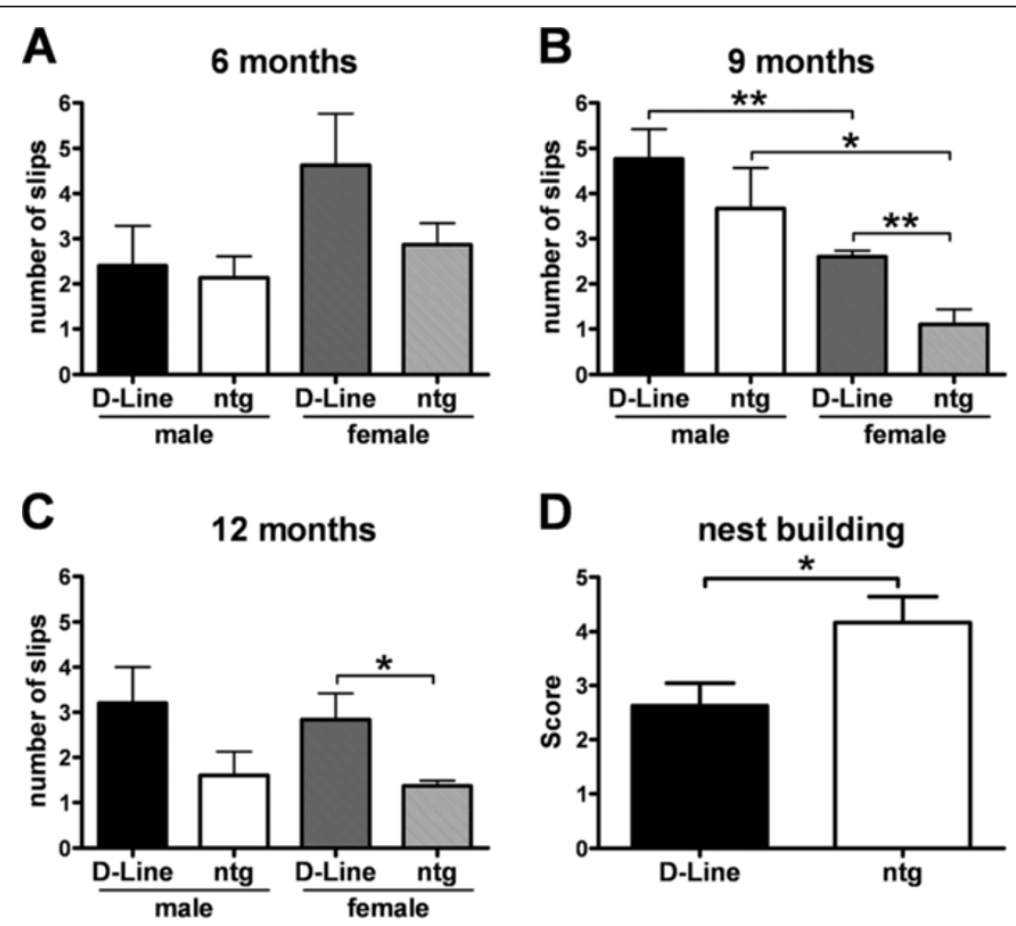

Figure $1 \mathrm{D}$-Line mice present impaired motor coordination. The number of slips by male and female D-Line mice compared to nontransgenic littermates were measured with the challenging beam walk test in 6 (A), 9 (B) and 12 (C) months old individuals. Graphs show mean \pm SEM; t-test. When analyzed by one way or two way ANOVA followed by Bonferroni's post hoc test, factor transgene, no significant changes were observed. (A-C) D-Line male: $n=6$; D-Line female: $n=6$; wt male: $n=6$; wt female: $n=6$. (D) Pooled data of either sex on nest building behavior of D-Line mice compared to non-transgenic littermates in 9 months old individuals. Graph represents the mean nest building score (scoring from 1-5). D-Line $(n=8) ; n t g(n=6)$. Graph shows mean \pm SEM; Mann-Whitney U-test. * $p<0.05$; ** $p<0.01$. 
12 months and only the significant difference between female D-Line and non-transgenic mice remained (Figure 1C). The significant differences shown in Figure $1 \mathrm{~A}-\mathrm{C}$ were detected by analyzing data with t-test. Analyses of the presented data for the factor gender by two way ANOVA followed by Bonferroni's post hoc test revealed a significant influence of the gender for transgenic as well as non transgenic mice $(\mathrm{p}<0.05$, data not shown). Analyses of data by two way ANOVA followed by Bonferroni's post hoc test for the factor transgene and by one way ANOVA did not reveal any significances. Analysis of the number of slips for progressive changes over age separated by sex showed only a significant improvement of non-transgenic female mice over age (two way ANOVA followed by Bonferroni's post hoc test, factor time; data not shown). The time and number of steps required to traverse the beam and the ratio of slips per step did not differ significantly between D-Line and non-transgenic littermates (two way ANOVA, one-way ANOVA and t-test). In order to verify that the observed motor differences between the D-Line mice and nontransgenic littermates were not caused by modifications of spontaneous activity or deficits in spatial learning, the cylinder test and the two-choice swim test were performed, and no significant effects were detected (data not shown). General health of each mouse was determined using the Irwin test-including the wire hanging test and vertical pole test, assessing physical characteristics and abnormalities, sensorimotor reflexes and motor abilitiesbut no significant differences were observed. Overall, all animals appeared healthy over the course of the study.

The nest building test was used to analyze D-Line mice compared to non-transgenic littermates at 9 months of age. D-Line mice showed a significantly reduced nest building behavior (Figure 1D). While non-transgenic mice built an almost perfect nest with the provided material, the D-Line mice shredded only about $50 \%$ of the nesting material and an easily identifiable nest site was missing. Since no significant differences between male and female D-Line mice were observed (data not shown), data of both sexes were pooled for Figure 1D. Taken together, our behavioral analysis argues for an impairment of motor coordination in transgenic mice during execution of challenging tasks, whereas overall motor activity is largely unaffected.

\section{Quantification of a-synuclein protein levels over age}

Analyses of h $\alpha$-Syn protein levels by ELISA showed a significant increase in the hippocampus at 12 months of age compared to 3 and 6 months old D-Line mice (Figure 2A). The increase was less pronounced in the striatum but was significant at 12 months compared to 3 and 6 months (Figure 2B). In order to investigate whether the progressive accumulation of ha-Syn in brain homogenates using ELISA could also be detected in situ we next analyzed expression levels of human and murine protein isoforms in the cortex, hippocampus, striatum and substantia nigra by quantification of immunofluorescent labeling using isoform-specific antibodies. In all analyzed brain areas the pan (murine and human) $\alpha$-Syn levels of D-Line mice did not differ from non-transgenic littermates, and in both genotypes the total protein levels did not change significantly over age in cerebral cortical (Figure 3A-B) and subcortical (Figure 4A-B) areas. However, analyses restricted to transgenic h $\alpha-S y n$, the same isoform that was analyzed biochemically by ELISA, showed significantly higher immunofluorescence signal intensity $(\mathrm{p}<0.001)$ in D-line mice compared to ntg mice already at 3 months of age in cortical areas (Figure 3C-D). Expression levels of ho-Syn in the striatum and the substantia nigra were also above baseline in D-line mice (Figure 4C-D) but were generally lower than in cortical areas. Despite these
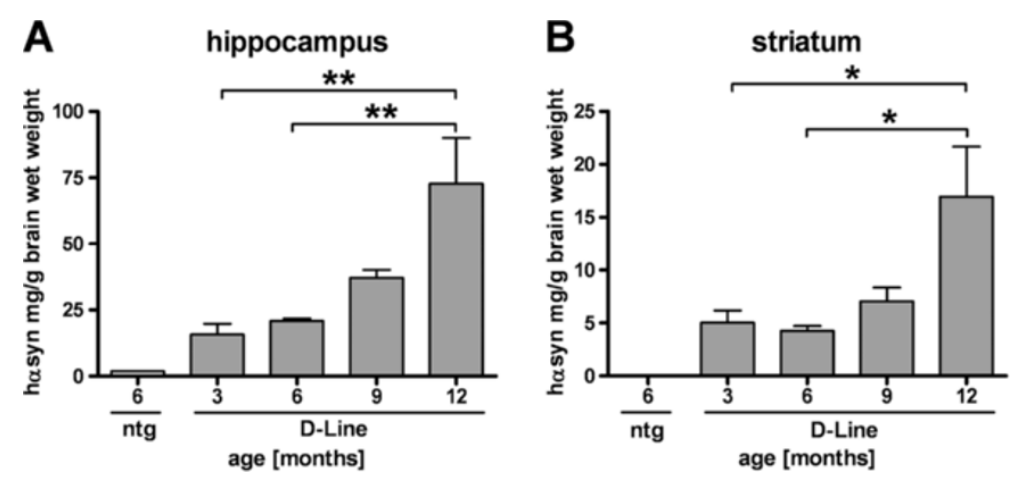

Figure 2 Increasing transgenic a-Synuclein protein levels in the brain of 3-12 months old D-Line mice. ELISA was used to analyze levels of ha-Syn in brain homogenates. Panels show ha-Syn expression levels of 3, 6, 9 and 12 months old D-Line mice in the hippocampus (A) and striatum (B) and 6 months old non-transgenic littermates. D-Line mice: 3, 9 and 12 months old $(n=6), 6$ months $(n=5)$, ntg $(n=1)$. Values of one animal were excluded by Grubb's Outlier test. Striatum ntg value $=0$. Data of the non-transgenic mouse were not included in statistical analyses. Graphs show mean \pm SEM; one-way ANOVA followed by Bonferroni's post hoc test. * $p<0.05$; ** $p<0.01$. 


\section{cortex}

A
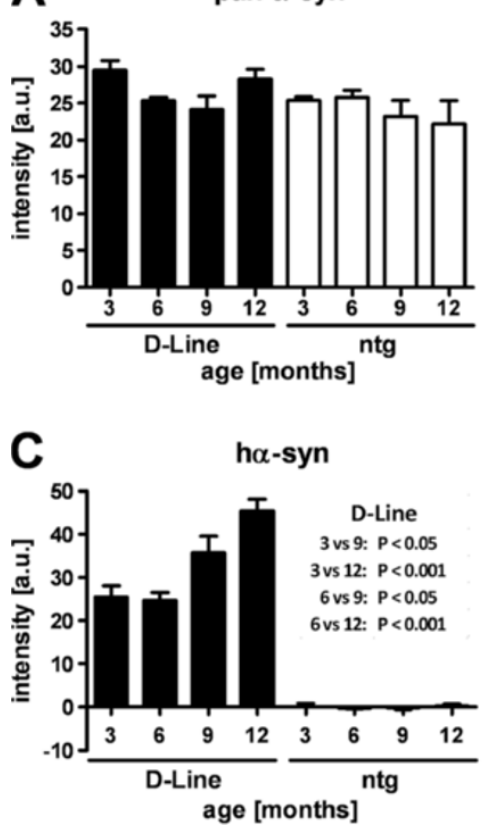

hippocampus
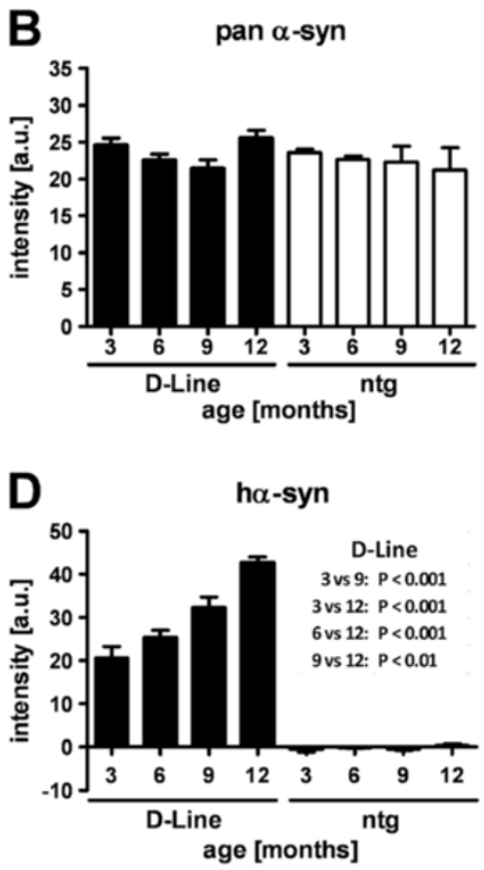

Figure 3 Quantitative analyses of a-Synuclein levels in cerebral cortex of 3-12 months old mice. Immunofluorescence intensity of pan a-Syn labeling (A, B) and transgenic ha-Syn labeling (C, D) in the cortex (left panels) and hippocampus (right panels). The expression levels of pan a-Syn are constant throughout life and do not differ between genotypes, whereas ha-Syn expression in D-Line mice doubles between 3 and 12 months of age. D-Line: 3 months $(n=8), 6$ months $(n=9), 9$ months $(n=6), 12$ months $(n=8)$; ntg mice: 3 months $(n=4), 6$ months $(n=4), 9$ months $(n=5), 12$ months $(n=3)$. Graphs show mean \pm SEM; one-way ANOVA followed by Bonferroni's post hoc test.

regional differences in total levels, an age-dependent significant increase of ho-Syn immunofluorescence could be observed in all four brain areas of D-Line mice (Figures 3C-D, 4C-D), consistent with the data obtained by ELISA. This result, together with the absence of any agerelated change in pan $\alpha$-Syn, raises the possibility that adaptive mechanisms may downregulate murine $\alpha$-Syn expression to ensure homeostatically appropriate protein levels throughout life. An alternative explanation for the finding of constant pan $\alpha$-Syn levels is that the pan-specific monoclonal antibody may have lower affinity for the human isoform compared to murine $\alpha$-Syn. This could potentially be assessed using an antibody that specifically detects only murine $\alpha$-Syn, but to our knowledge such a reagent is not available.

\section{Distribution pattern of human, murine and phosphorylated a-synuclein protein}

Next we investigated the distribution patterns of ha-Syn and pan $\alpha$-Syn isoforms by double-immunofluorescent labeling throughout the brain (Figure 5A-B). High levels of ho-Syn were detected in the pontine nucleus and in the cortex, including the cortical part of the amygdala and the hippocampus. High levels of h $\alpha$-Syn accumulation were also detected in the striatum, ventral hypothalamus and in the olfactory bulb. Double-immunofluorescence for h $\alpha$-Syn and a $\mathrm{N}$-terminal epitope of both murine and human $\alpha / \beta$-synuclein $(\mathrm{N}-\alpha / \beta$-Syn) at higher magnification revealed that transgenic h $\alpha$-Syn obviously accumulates in somata and proximal dendrites. This is also evident in layers with few neuronal somata but high density of neuropil (Figure 5C-D), suggesting subcellular targeting of overexpressed h $\alpha$-Syn to both dendrites and axons. In contrast, $N-\alpha / \beta-S y n$ is preferentially expressed in synaptic terminals, notably in the stratum lucidum of hippocampal CA3 (Figure 5C,E) and less obvious in the neocortex (Figure 5D, F), consistent with previous reports on largely presynaptic expression in wild type mice [23,24].

Next, we investigated the expression pattern of phosphorylated protein (Figure 6) using an antibody specifically directed against an epitope including the phosphorylatedSerine 129 residue of the human $\alpha$-Synuclein isoform (pS129-ho-Syn). Phosphorylation at residues S87 and S129 is of particular interest for synucleinopathy research because it has been argued that phosphorylation at these residues might modulate the formation of protein aggregations, e.g. inclusion bodies and fibrillary structures [25-27]. We found that in the hippocampus and neocortex, the subcellular expression of pho-Syn is largely restricted to neuronal nuclei (Figure 6), as evident from the overlay with the nuclear dye DAPI (Figure 6C). Qualitative analysis of pS129-h $\alpha-$ Syn suggests that the vast majority of neuronal 


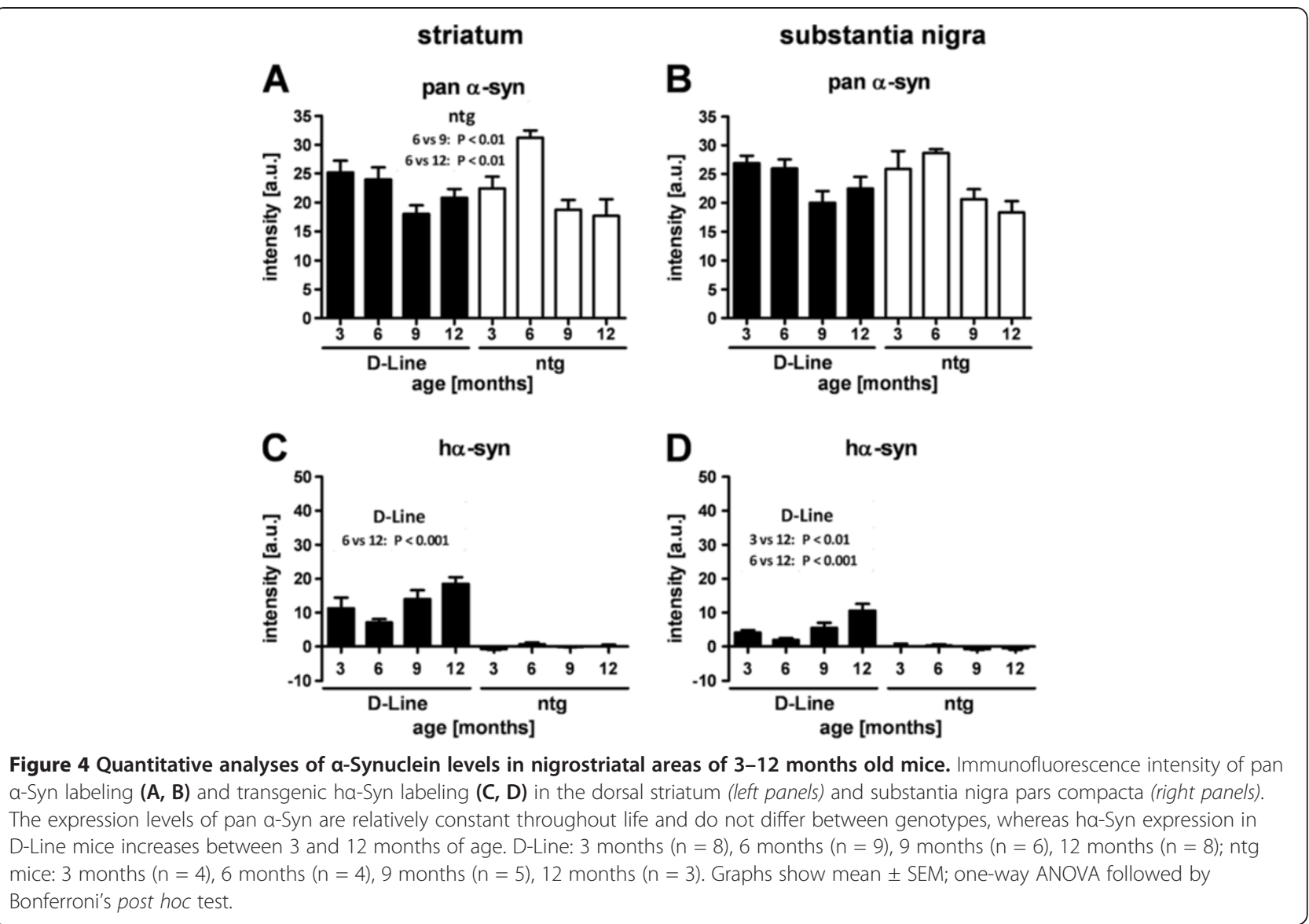

somata expressing the h $\alpha$-Syn isoform show easily detectable levels of pS129-ho-Syn. However, we found no evidence for expression in synaptic terminals or pathological intracellular accumulations in D-Line mice of up to 9 months. In contrast to the pS129S residue, phosphorylated S87 ho-Syn is undetectable in D-Line mice [27].

\section{Identification of a-synuclein-expressing neurons}

In order to identify neuronal populations that accumulate ho-Syn, several multichannel immunofluorescence experiments were performed. Using antibodies against GAD67 and tyrosine hydroxylase we found that ho-Syn is expressed in subpopulations of GABAergic and dopaminergic neurons, respectively, of the olfactory bulb (Figure 7A), and in GABAergic interneurons of cortical areas (Figure 7B-C). Since some GABAergic somata in the hippocampal formation show little or even no GAD67 immunoreactivity [28] we alternatively identified interneurons by expression of the neuregulin receptor ErbB4 that is a selective marker for a subset of cortical GABAergic neurons [29-31]. We detected h $\alpha$-Syn in a small number of ErbB4-positive interneurons in the cornu ammonis and dentate gyrus but not on microglia identified by Iba1 immunoreactivity (Figure 7D). With regard to glutamatergic principal neurons, h $\alpha$-Syn was not detectable in mitral cells of the olfactory bulb (Figure 8A), but strong expression was evident in subsets of neocortical and hippocampal pyramidal cells (Figure 8B-C). We noted the occurrence of strong ho-Syn immunoreactivity in some regions of the adult brain featuring immature and migrating neurons (Figure $9 \mathrm{~A}-\mathrm{G}$ ), such as the ventricular zone and the rostral migratory stream. Using multichannel immunofluorescence, we confirmed ho-Syn expression in immature migrating neurons that were identified by several established markers such as doublecortin, PSA-NCAM and ErbB4 ([32-36]. In contrast, h $\alpha$-Syn immunoreactivity was consistently absent from immature neurons in the hippocampal dentate gyrus (Figure $9 \mathrm{H}$ ), suggesting that h $\alpha$-Syn expression is not a unifying feature of migrating or maturing neurons in adult D-Line mice. Taken together, our data show that strong ho-Syn immunofluorescence occurs region-specifically in heterogeneous populations of neurons of the adult brain.

\section{Discussion}

This study was designed to characterize the time course and progression of the pathology in D-Line mice, a model of $\alpha$-Syn accumulation similar to DLB. We found 


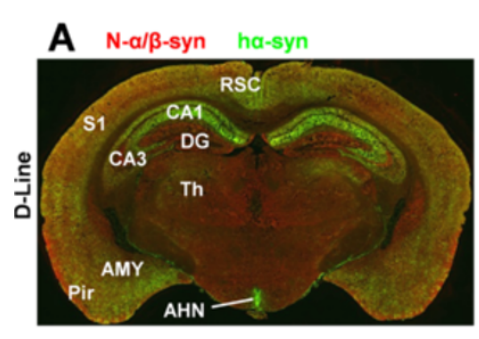

Hippocampus
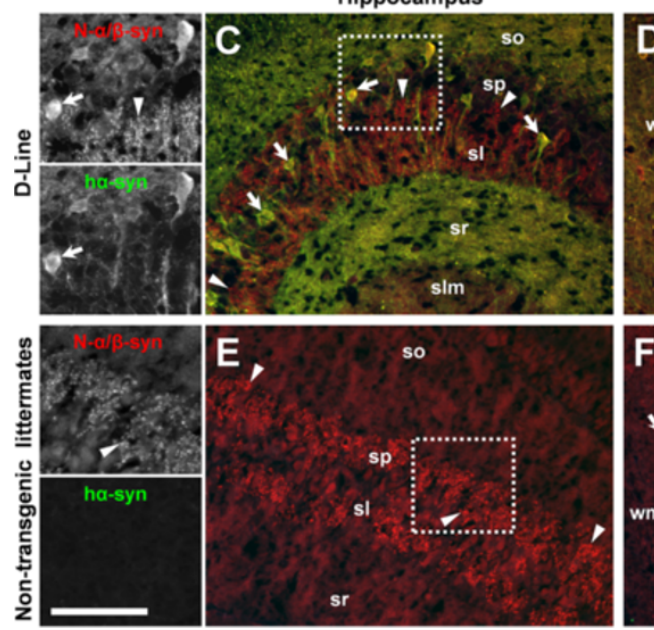

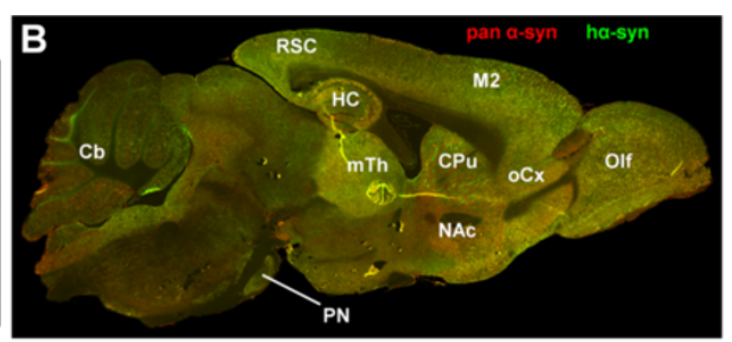

Neocortex
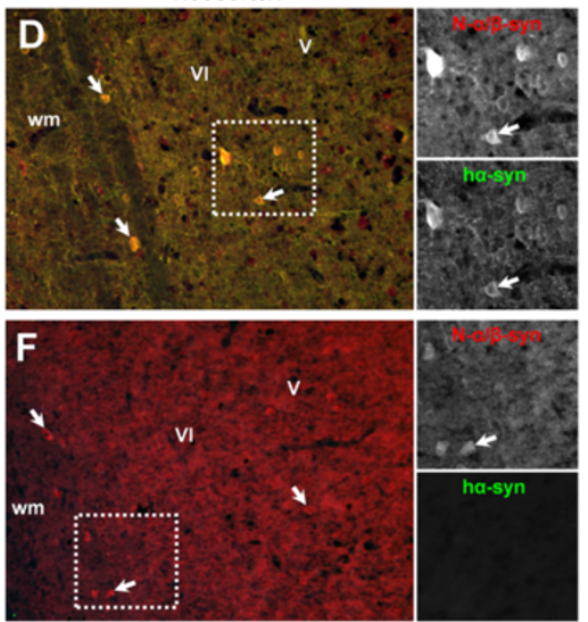

Figure 5 Region-specific expression patterns of human a-Synuclein versus murine Synuclein in neocortical and hippocampal areas. Coronal (A) and sagittal (B) overview images demonstrate that transgenic expression of ha-Syn (green channel) is most prominent in the cerebral cortex (RSC, S1, Pir, CA1-3, M2, oCx), subcortical telencephalic structures (AMY, CPu, NAc, Olf), medial thalamic nuclei (mTh), the arcuate hypothalamic nucleus (AHN), and the pontine nucleus (PN) in transgenic mice. Please note that expression in the hippocampal formation (HC) is restricted to CA1-3 but is largely absent from dentate gyrus (DG) (A). In contrast, using antibodies directed against either (A) a speciesindependent N-terminal epitope of $\mathrm{N}-\mathrm{a} / \mathrm{\beta}$-Syn or (B) a species-independent epitope of pan a-Syn shows expression throughout most areas of the brain including subcortical structures (red channel). Higher magnification reveals accumulation of transgenic ha-Syn in a subset of cells (arrows) in the stratum pyramidale (sp) of hippocampal CA3 (C) and in cortical layers V-VI (D). Neuropil in strata oriens (so) and radiatum (sr) shows high haSyn immunoreactivity, which in contrast is mostly absent arrowheads from strata lucidum (sl) and lacunosum moleculare (sIm) (C). In nontransgenic mice, hippocampal expression of murine $\alpha / \beta-S y n(E)$ is restricted to mossy fiber terminals in stratum lucidum (arrowheads) but is absent from neuronal somata, whereas in the neocortex (F) some cells close to white matter (wm) are $\alpha / \beta$-Syn positive arrows. Please note the specificity of the antibody directed against the human isoform of a-Syn, as evident from absence of immunoreactivity on non-transgenic tissue (green channel in E, F). Scale bar: 2 mm (A, B), 150 m (C-F). Abbreviations: amygdala (AMY), cerebellum (Cb), cornu ammonis areas 1-3 (CA1-3), caudate/putamen (CPu), motor cortex (M2), nucleus accumbens (NAc), orbital frontal cortex (oCx), olfactory bulb (Olf), piriform cortex (Pir), retrosplenial cortex (RSC), somatosensory cortex (S1), thalamus (Th).

progressive motor coordination deficits at 9 and 12 months of age complemented by alterations in the nest building behavior. These deficits were accompanied by a parallel age-dependent increase in the levels of ho-Syn in somata and neuritic processes of a subset of neocortical, limbic and nigrostriatal system cells. The mechanisms by which accumulation of ha-Syn in these circuitries might result in functional deficits are not completely clear. Recent findings on changes in expression levels of neurotrophic factors in ho-Syn transgenic mice [37] suggest that altered BDNF levels could be linked to onset and progression of Parkinson's disease [38].

The progressive motor alterations in the challenging beam walk test detected in D-Line mice are consistent with previous studies using the rotarod and pole test
$[5,15]$ and support a dysfunction of the nigrostriatal system. Also supporting this possibility, previous studies have shown that D-Line mice of either sex generally perform worse compared to non-transgenic littermates; however, at the age of 9 months D-Line and nontransgenic male mice consistently slip more often during the challenging beam walk test than females. In transgenic mice the sex difference seems to increase up to the age of 9 months, suggesting that h $\alpha$-Syn has an earlier impact on motor performance in male than in female mice. Interestingly, these results are reminiscent of sex differences in humans where female Parkinson patients show a delayed onset of the disease compared to males [39].

Nest building behavior is an intrinsic behavior in both female and male mice that requires proper fine motor 


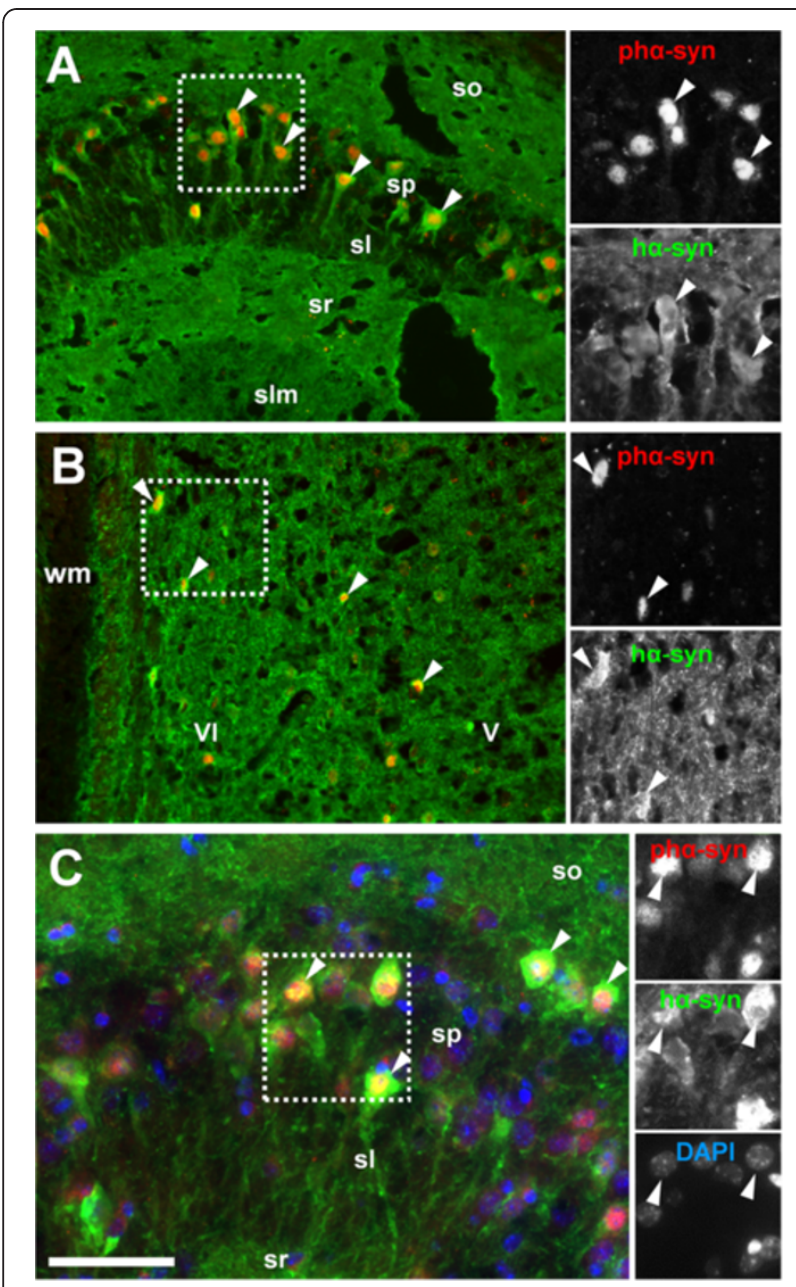

Figure 6 Phosphorylated human a-Synuclein is targeted to nuclei but is undetectable in neurites. Immunoreactivity for transgenic ha-Syn (green channel) is evident in a subset of pyramidal neurons $(\mathbf{A}, \mathbf{C})$ in the hippocampal area CA3 and (B) in the dorsolateral neocortex (arrowheads); in either area the transgenic isoform is targeted to both somata and neurites. Using an antibody against human protein phosphorylated at S129 (pha-Syn, red channel), immunoreactivity is strong in most neurons that are positive for ha-Syn but is spatially restricted to neuronal nuclei, as is evident from co-localization with DAPI (arrowheads) (C). Scale bar: $150 \mu \mathrm{m}$ (A, B), $100 \mu \mathrm{m}$ (C). Abbreviations: cornu ammonis areas 1-3 (CA1-3), stratum oriens (so), stratum pyramidale (sp), stratum lucidum (sl), stratum radiatum (sr), stratum lacunosum moleculare $(\mathrm{s} / \mathrm{m})$, white matter (wm), cortical layer $\mathrm{V}$ and $\mathrm{VI}(\mathrm{V}$ and $\mathrm{VI})$.

skills. The nest is important for sustaining body temperature and provides shelter during birth and rearing of offspring. Different lesioning studies provide evidence that nest building behavior strongly depends on the proper function of the hippocampus, caudate putamen and ventral mesencephalic tegmentum [40-42]. Moreover, nest building was shown to be dopamine- and enkephalin-dependent [43]. All these brain systems are known to be highly relevant for PD $[44,45]$, suggesting that the nest building test is an appropriate tool for assessing Parkinson-associated impairments. Therefore, our here presented data of nest building and motor deficits in the beam walk test suggest, that D-Line transgenic mice represent with the most common behavioral symptoms of PD.

Analyses of h $\alpha$-Syn levels in the brain by ELISA showed an age dependent increase of transgenic protein levels in the hippocampus and striatum between 3 and 12 months. Using quantitative analysis of immunofluorescence against ho-Syn we could verify this result in situ. Interestingly, however, we detected neither genotype-dependent nor age-dependent increases in total (human and murine) $\alpha$ Syn levels. Given that under the PDGF- $\beta$ promoter the mRNA expression of $\alpha$-Syn is stable throughout life, the progressive accumulation of h $\alpha$-Syn protein in the brains of the transgenic mice indicates deficits in clearance. This is consistent with previous studies showing alterations in the autophagy pathway in the

Dline mice $[14,46]$, these alterations were reversed pharmacologically with rapamycin [14] or genetically with Beclin1 [17] or Atg7 [14] and worsen with shAtg7 [14] or Bafilomycin-A1 [46]. In addition, the finding of constant total $\alpha$-Syn levels despite the parallel accumulation of transgenic h $\alpha$-Syn protein raises the possibility that the expression of endogenous murine $\alpha$-Syn might be a tightly regulated mechanism. Overexpression of ha-Syn could therefore be a trigger for homeostatic downregulation of the murine isoform. Moreover, total $\alpha$-Syn immunoreactivity even decreased slightly in the substantia nigra of non-transgenic animals suggesting that reduction of $\alpha$-Syn levels in the nigrostriatal dopaminergic pathway of older mice is a normal event during aging in healthy rodents, consistent with reports by other groups [47,48].

We identified subsets of transgene expressing neurons as inhibitory GABAergic interneurons or excitatory glutamatergic pyramidal neurons in cortical areas. With respect to dopaminergic cells, we found co-expression of h $\alpha$-Syn and tyrosine hydroxylase in many neurons of the olfactory bulb, in contrast to the substantia nigra where only low levels of h $\alpha$-Syn were detectable. We also detected h $\alpha$-Syn immunoreactivity in some GABAergic interneurons of the olfactory bulb but, in contrast to cortical areas, not in glutamatergic principal neurons (mitral cells). Overall, this pattern is consistent with the reported expression of PDGF- $\beta$ in different types of neurons [49,50]. Our investigation of ho-Syn phosphorylation at residue S129 shows that immunoreactivity is largely restricted to the nuclei of neurons that express high levels of the transgenic protein. Of note, we found no indication of granular or fibrillarylike accumulations of pS129-ho-Syn, opening the question whether this nuclear immunoreactivity reflects regular physiological events or rather indicates progression towards neuropathology consistent with previous reports [51]. Finally, consistent with previous studies [52] we found that h $\alpha$-Syn accumulates in areas featuring immature neurons, 

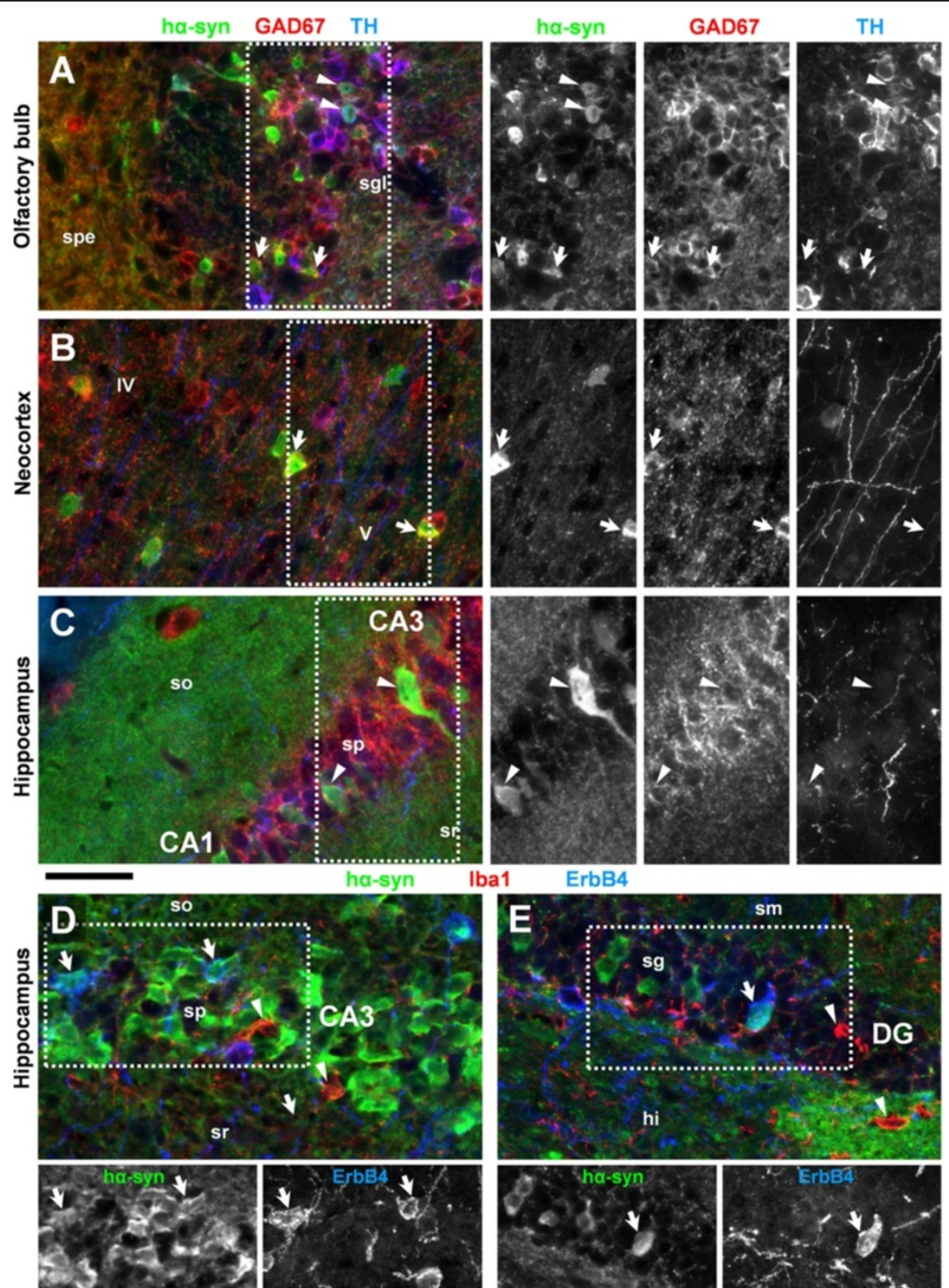

sm
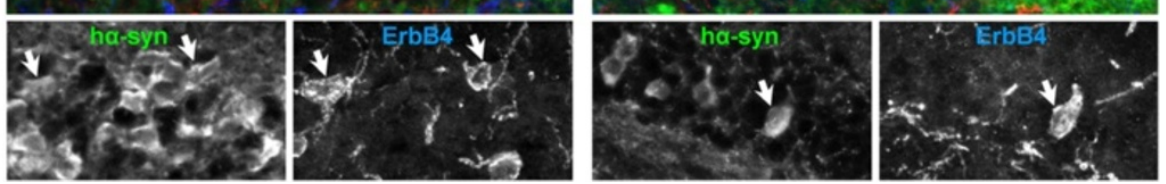

Figure 7 Region-specific expression of human a-Synuclein in different subpopulations of neurons. Triple immunofluorescent labeling reveals expression of transgenic ha-Syn (green channel) in different types of neurons. (A) ha-Syn immunoreactivity is evident in a subset (arrowheads) of dopaminergic neurons ( $\mathrm{TH}$, blue channel) in the glomerular layer (sgl), and occasionally (arrows) in GABAergic interneurons (GAD67, red channel) throughout the olfactory bulb. (B) A subset of neocortical ha-Syn-positive neurons (arrows) are immunoreactive for the interneuron marker GAD67 (red channel); however, this did not occur in the hippocampus (arrowheads) probably due to known low expression levels of GAD67 in some types of interneurons (C). Using ErbB4 immunoreactivity as an alternative marker for GABAergic neurons, we found haSyn expression in a subset of interneurons (arrows), but not in Iba1-immunoreactive microglia (arrowheads), in hippocampal area CA3 (D) and in the dentate gyrus (E). Abbreviations: dentate gyrus (DG), glutamic acid decarboxylase 67 kD (GAD67), tyrosine hydroxylase (TH), stratum plexiforme externum (spe), stratum oriens (so), stratum pyramidale (sp), stratum radiatum (sr), stratum moleculare (sm), stratum granulosum (sg), hilus (hi) cortical layer $\mathrm{V}$ and $\mathrm{VI}(\mathrm{V}$ and $\mathrm{VI})$, cornu ammonis area 1/3 (CA1/3). Scale bar $=50 \mu \mathrm{m}$. 

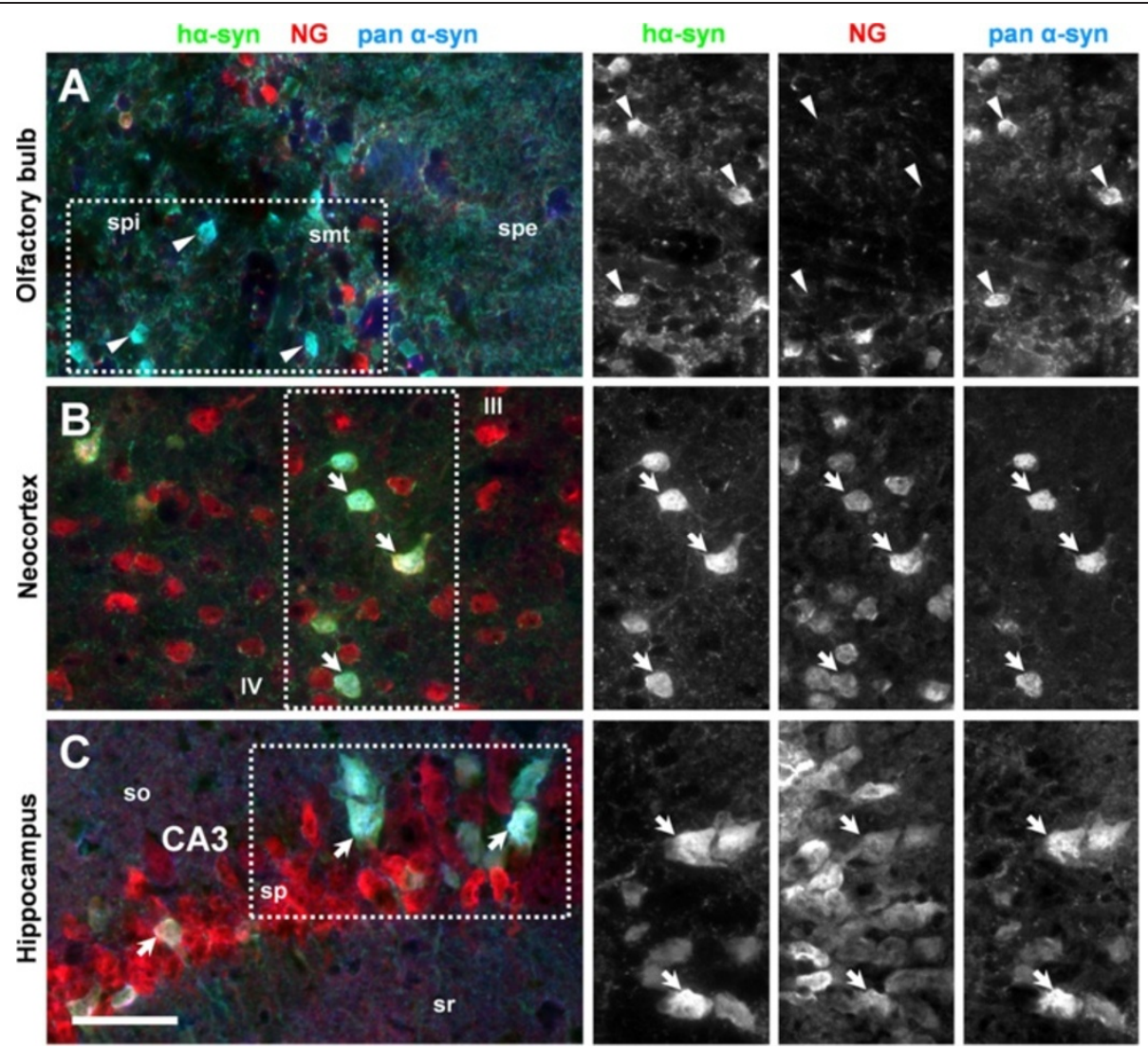

Figure 8 Expression of human a-Synuclein in populations of principal neurons. Triple fluorescent labeling reveals that immunoreactivity of both ha-Syn (green channel) and pan a-Syn (blue channel) is absent from neurogranin-positive mitral cells (NG, red channel) in the olfactory bulb (arrowheads in A). In contrast, a subset of neocortical (B) and hippocampal (C) pyramidal neurons expresses a-Syn; co-localization of all three color channels (arrows) is indicated by the occurrence of whitish pixels. Single channel images are rotated clockwise in panels $\mathbf{A}$ and $\mathbf{C}$. Abbreviations: neurogranin (NG), stratum plexiforme externum/internum (spe/i), stratum mitrale (smt), stratum oriens (so), stratum pyramidale (sp), stratum radiatum (sr), cortical layers III and IV (III and IV), cornu ammonis area 3 (CA3). Scale bar $=50 \mu \mathrm{m}$.

such as the subventricular zone and the rostral migratory stream. Accumulation of ho-Syn in these areas results in reduced proliferation and survival of neuroblasts [52], however, the functional relevance of these alterations is yet unknown. Interestingly, we found no indication of ho-Syn immunoreactivity in maturing neurons of the dentate gyrus, indicating that ho-Syn expression is not a common feature of all populations of immature or migrating neurons. Additional studies are required to investigate whether these regional differences have functional relevance that may affect survival rates or maturation of these cells.

\section{Conclusions}

Our data suggest that ho-Syn accumulates in subsets of glutamatergic, dopaminergic, and GABAergic, neuronal populations in the neocortex, limbic system and nigrostriatal system similar to the distribution of ho-Syn in DLB. Immunoreactivity for human protein phosphorylated at residue S129 is restricted to neuronal somata, whereas much of the additional immunofluorescent signal from h $\alpha$ Syn protein not phosphorylated at the S129 residue comes from areas with few neuronal somata but dense neuropil, thus mimicking the distribution of the endogenous murine $\alpha$-Syn isoform. We also detected progressively increasing levels of ha-Syn protein during adulthood using different experimental approaches, and concomitant impairment of motor coordination. In contrast, the level of total $\alpha$-Syn is constant between 3-12 months, possibly due to a compensatory downregulation of the endogenous $\alpha$-Syn isoform. We conclude that different readouts, i.e. behavioral, biochemical and histological, can detect structural and functional pathology in the D-Line mouse model, and that this animal model is highly valuable for PD-related research and drug development.

\section{Methods}

Animals

For this study we used male and female mice overexpressing human wild type $\alpha$-Syn under the regulatory 
control of the platelet-derived growth factor (PDGF- $\beta$ ) promoter with a C57BL/6xDBA background (D-Line, [5]). All experiments were performed with hemizygous D-Line mice and corresponding non-transgenic littermates. Animals were housed in individually ventilated cages on standardized rodent bedding (Rettenmayer ${ }^{\circledR}$ ).
The room temperature was kept at approximately $24^{\circ} \mathrm{C}$ and the relative humidity between $40-70 \%$. Mice were housed under constant light-cycle (12 hours light/dark). Dried pelleted standard rodent chow (Altromin ${ }^{\circledR}$ ) and normal tap water were available to the animals ad libitum. The health and well-being of each individual animal was monitored
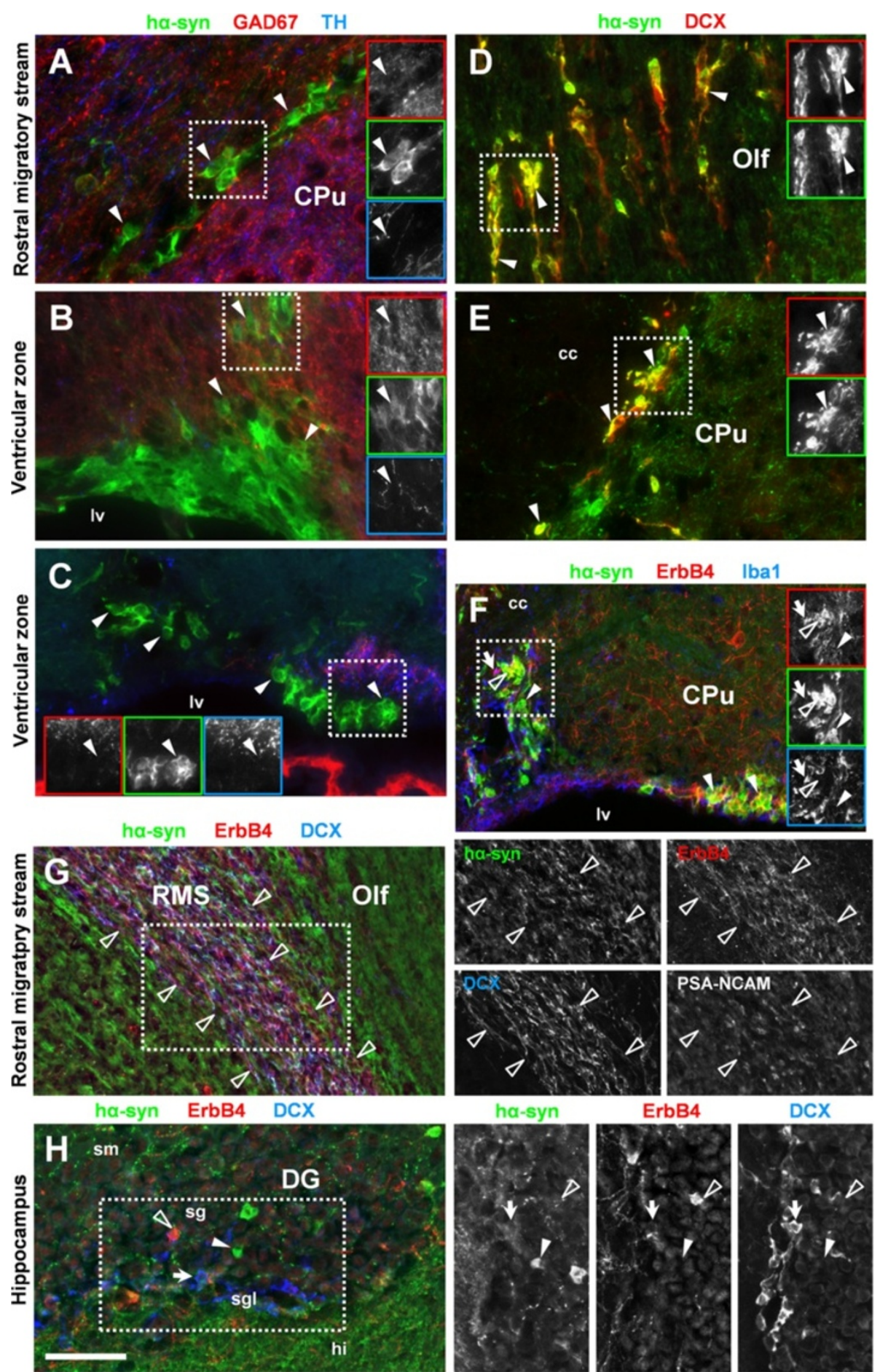

ha-syn
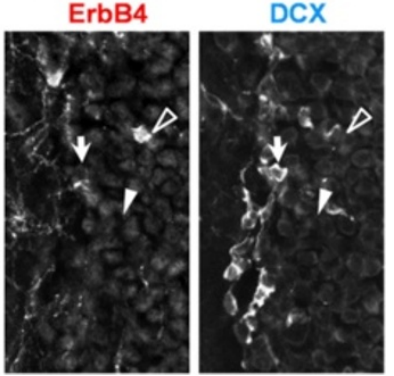

Figure 9 (See legend on next page.) 
(See figure on previous page.)

Figure 9 Human a-Synuclein is strongly expressed in immature neurons in a region-specific pattern. Immunofluorescent labeling of ha-Syn (green channel) in different regions of the brain shows strong expression of transgenic a-Syn (arrowheads) in immature neurons in the rostral migratory stream (RMS) (A, D, G) and in the ventricular zone (VZ) (B, C, E, F). We found no coexpression with either GAD67 or TH (A, B, C), whereas many ha-Syn-positive cells were immunoreactive for doublecortin (DCX) in the RMS (D) and the VZ (E), indicating that ha-Syn is expressed in subpopulations of immature migrating neurons. (F) We also found co-expression of ha-Syn and ErbB4 in the VZ (open arrowhead in F) and the RMS (G), whereas ha-Syn was not expressed in microglia immunoreactive for Ibal (arrow in $\mathbf{F}$ ). The VZ and the RMS were identified by immunoreactivity for DCX, ErbB4, or PSA-NCAM (G). (H) In contrast to the VZ and RMS, we found no indication for expression of either ha-Syn (arrowhead) or ErbB4 (open arrowhead) in DCX-positive immature neurons (arrow) in the subgranular layer (sgl) of the hippocampal dentate gyrus (DG). Single channel images are rotated clockwise in panel H. Abbreviations: caudate/putamen (CPu), corpus callosum (cc), glutamic acid decarboxylase $67 \mathrm{kD}$ (GAD67), hilus (hi), lateral ventricle (Iv), olfactory bulb (Olf), stratum granulosum (sg), stratum moleculare (sm), tyrosine hydroxylase $(T H)$, doublecortin (DCX). Scale bar $=50 \mu \mathrm{m}(\mathbf{A}-\mathbf{E}, \mathbf{H}), 70 \mu \mathrm{m}(\mathbf{F}, \mathbf{G})$.

regularly. Animal studies conformed to the Austrian guidelines for the care and use of laboratory animals and were approved by the Styrian Government, Austria.

\section{Behavioral tests}

For behavioral tests 6, 9 and 12 months old animals were used. 12 males (6 tg and $6 \mathrm{ntg}$ ) and 12 females (6 tg and 6 ntg) were analyzed per age group. The challenging beam walk test was carried out with all mice as previously described [53]. In short, mice were trained to traverse the length of a beam starting at the widest section and ending at the narrowest, most difficult section. The narrow end of the beam led directly into the animal's home cage. Mice received two days of training before testing. In order to increase difficulty on the day of testing, a wire mesh of corresponding width was placed over the beam. On the testing day mice were required to run five trials. Mice were video-taped while traversing the grid-surfaced beam. Videotapes were viewed and rated in slow motion for slips, number of steps, slips per step and time to traverse. After normal distribution was verified by KolmogorovSmirnov test, group differences were calculated by oneway ANOVA, two-way ANOVA followed by Bonferroni's post hoc test, factors transgene, gender and time, and unpaired t-test, using GraphPad Prism 4.03.
To test the individual nest building behavior, 9 months old mice were housed separately overnight in cages containing wood chip bedding and one $5 \mathrm{~cm}$ square piece of pressed cotton (nestlet). No other nesting material was provided. The nestlet was introduced on the day before the evaluation of the nest. The following morning the nest was assessed, according to a five-point scale [54]. If the nestlet was not noticeably touched it was scored with 1 point. A near perfect nest, in which at least $90 \%$ of the nestlet was used, was scored with 5 points. After normal distribution was unconfirmed by KolmogorovSmirnov test, group differences were calculated by Mann-Whitney U-test, using GraphPad Prism 4.03.

\section{Tissue preparation}

Mice were deeply anesthetized by Isoflurane (BAXTER ${ }^{\circledR}$, Austria) and the thorax was opened to excavate the heart. Animals were flush-perfused transcardially with $0.9 \%$ saline through the left ventricle. The hemispheres were divided at midline. The right hemisphere was immersion fixed in $4 \%$ paraformaldehyde in $0.1 \mathrm{M}$ phosphate buffer, $\mathrm{pH}$ 7.4, for $1 \mathrm{~h}$ at room temperature (RT), cryoprotected in 30\% sucrose, and snap-frozen in dry ice-cooled isopentane for further histological evaluations. The left hemisphere was dissected into hippocampus, striatum and rest

Table 1 List of primary antibodies

\begin{tabular}{|c|c|c|c|c|c|}
\hline Species & Antigen & Clone & Source & Item \# & Dilution \\
\hline rat & Human a-Synuclein & $15 \mathrm{G} 7$ & Enzo Life Sciences, Plymouth Meeting, PA & 804-258-L001 & $1: 20$ \\
\hline mouse & Human phospho a-Synuclein & EP1536Y & Abcam, Cambridge, UK & ab51253 & $1: 2000$ \\
\hline mouse & a-Synuclein & 4D6 & Abcam & ab1903 & $1: 500$ \\
\hline goat & a/ß-Synuclein, N-terminal & poly & Santa Cruz Biotechnology, Santa Cruz, CA & sc-7012 & 1:300 \\
\hline goat & Doublecortin & poly & Santa Cruz Biotechnology & sc-8066 & 1:200 \\
\hline rabbit & Iba1/AlF1 & poly & ProteinTech Group, Chicago, IL & 10904-1-AP & 1:500 \\
\hline rabbit & Tyrosine hydroxylase & poly & Novus Biologicals, Cambridge, UK & NB300-109 & 1:1000 \\
\hline rabbit & Neurogranin & poly & Millipore, Temecula, CA & AB5620 & 1:1000 \\
\hline mouse & GAD67 & $1 \mathrm{G} 10.2$ & Millipore & MAB5406 & $1: 2000$ \\
\hline mouse & PSA-NCAM & $2-2 B$ & Millipore & MAB5324 & $1: 200$ \\
\hline mouse & N-ErbB4 & $\mathrm{H} 4.77 .16$ & LabVision, Fremont, CA & MS-270 (mAb-77) & $3 \mu \mathrm{g} / \mathrm{ml}$ \\
\hline rabbit & C-ErbB4 & $m A b-10$ & Buonanno Lab, NIH; Vullhorst et al., 2009 & $m A b-10$ & $3 \mu \mathrm{g} / \mathrm{ml}$ \\
\hline
\end{tabular}


brain, shock-frozen on dry ice, and stored at $-80^{\circ} \mathrm{C}$ for biochemical ho-Syn determination.

\section{Biochemistry}

We analyzed expression levels of ho-Syn in the hippocampus and striatum of D-Line mice and non-transgenic littermates at different ages: D-Line: 3, 9 and 12 months $(\mathrm{n}=6), 6$ months $(\mathrm{n}=5)$; ntg: 6 months $(\mathrm{n}=1)$. Total protein was extracted from brain samples by homogenization in 8 volumes guanidine buffer $(5 \mathrm{M}$ guanidine $\mathrm{HCl}$, $50 \mathrm{mmol} / \mathrm{L}$ TrisHCl, $\mathrm{pH}$ 8.0). The homogenates were mixed for $4 \mathrm{~h}$ at RT. Samples were then diluted 500x (hippocampus), 100x (striatum) with cold reaction buffer (2.68 mmol/L KCl, $1.47 \mathrm{mmol} / \mathrm{L} \mathrm{KH}_{2} \mathrm{PO}_{4}, 136.89 \mathrm{mmol} / \mathrm{L}$ $\mathrm{NaCl}, 8.1 \mathrm{mmol} / \mathrm{L} \mathrm{Na} \mathrm{HPO}_{4}, 5 \% \mathrm{BSA}, 0.03 \%$ Tween-20 and protease inhibitor cocktail) and centrifuged at $16.000 \mathrm{~g}$ for $20 \mathrm{~min}$ at $4^{\circ} \mathrm{C}$. Supernatants were analyzed for total hoSyn concentrations by ELISA ( $\mathrm{Hu} \alpha$-Synuclein ELISA Kit \#KHB0061, Invitrogen) following the manufacturer's protocol. Group differences were statistically analyzed by excluding outliers using Grubb's test and subsequent oneway ANOVA followed by Bonferroni's post hoc test, using GraphPad Prism 4.03.

\section{Histology}

We quantitatively investigated tissue obtained from mice at different ages (Figures 3-4). D-Line / ntg: 3 months $(\mathrm{n}=8 / 4) ; 6$ months $(\mathrm{n}=9 / 4) ; 9$ months $(\mathrm{n}=6 / 5)$; 12 months $(\mathrm{n}=8 / 3)$. A natural $\alpha$-Syn knockout line from Harlan (C57BL/6JOlaHsd) served as negative control to test for antibody specificity (Additional file 1).

Qualitative multichannel immunofluorescence experiments (Figures 5-9) were performed at RT on sagittal cryosections $(10 \mu \mathrm{m}$ thick; systematic uniform random sampling) of adult mice (age 9 months, $\mathrm{n}=3$ per genotype, mixed sex) using the following protocol: Wash cryosections $2 \times 5 \mathrm{~min}$ in $0.05 \mathrm{M}$ tris-buffered saline (TBS, $\mathrm{pH}$ 7.6) with $0.25 \%$ Triton X-100, block $1 \mathrm{~h}$ with MOM blocking reagent (Vector, Burlingame, CA), wash $2 \times 2 \mathrm{~min}$, incubate $5 \mathrm{~min}$ in MOM diluent, incubate $40 \mathrm{~h}$ at $4{ }^{\circ} \mathrm{C}$ in new MOM diluent with primary antibodies, wash $3 \times 5 \mathrm{~min}$, incubate secondary antibodies $1 \mathrm{~h}$ in MOM diluent wash $3 \times 5$ min, mount with Mowiol.

The expression of transgenic h $\alpha$-Syn was detected with a rat monoclonal antibody (clone 15 G7) directed against residues 116-131 near the C-terminus of ha-Syn; this antibody does not bind to murine $\alpha$-Syn. h $\alpha$-Syn phosphorylated at Serine 129 (pS129-h $\alpha$-Syn) was visualized with a rabbit monoclonal antibody (clone EP1536Y). We detected $\alpha / \beta$-Synuclein expression using a goat polyclonal antibody raised against an $\mathrm{N}$-terminal sequence of $\alpha$-Syn of human origin $(\mathrm{N}-\alpha / \beta-\mathrm{Syn})$; this antibody labels both murine and human isoforms of $\alpha / \beta$-Syn. A pan-specific (pan $\alpha$-Syn) mouse monoclonal antibody (clone 4D6) was used to detect both murine $\alpha$-Syn and h $\alpha$-Syn. Primary anti- $\alpha$-Syn antibodies were tested for specificity on brain sections of $\alpha$-Syn knockout mice as shown in a supplementary figure (Additional file 1). Detailed information on all primary antibodies used in this study is provided in Table 1.

Secondary antibodies donkey anti-rat, donkey antimouse, donkey anti-rabbit, and donkey anti-goat were labeled with Cy2/DyLight488, Cy3, or Cy5/DyLight649 fluorophores (Jackson ImmunoResearch, West Grove, PA); all secondary antibodies were highly cross-adsorbed (ML quality) to prevent unspecific cross-reactivity. Specificity of secondary antibodies was assessed by omitting primary antibodies on parallel section as shown in an additional file (Additional file 1). Controls were routinely executed together with regular experiments.

Images for quantitative analysis were recorded with an Axio $\mathrm{mRm}$ camera mounted on AxioImager Z1 epifluorescence microscope at 10x magnification. Exposure time and additional settings were kept constant for all images used in quantification. Camera was set to the linear default. Regions of interest (ROI) were defined by individual delineation of the cortex, hippocampus and substantia nigra, and total $\alpha$-Syn immunofluorescence signal was determined by integrating pixel intensity throughout the ROI using ImageProPlus Software (Version 6.2). Five sections per brain region were analyzed deriving from five different systematically chosen medio-lateral levels. After normal distribution was verified by Kolmogorov-Smirnov test, group differences in histological variables were calculated by one-way ANOVA followed by Bonferroni's post hoc test, using GraphPad Prism 4.03. Epifluorescence z-stack images (8-10 z-levels, $0.3 \mu \mathrm{m}$ apart, $20 \%$ overlay) presented in the figures were obtained at 40x magnification and were collapsed using the Extended Focus function in AxioVision (v4.8) software.

\section{Additional file}

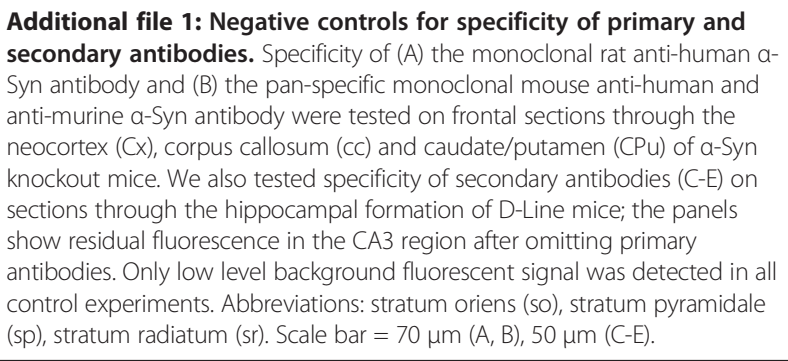

\section{Abbreviations}

(ha-Syn): Human a-synuclein; (DLB): dementia with Lewy bodies;

(DCX): doublecortin; (ErbB4): v-erb-a erythroblastic leukemia viral oncogene homolog 4; (GAD67): glutamic acid decarboxylase 67 kD; (Iba1/AIF1): ionized calcium binding adaptor molecule 1/allograft inflammatory factor 1; (MSA): multiple system atrophy; (ntg): non-transgenic; (PD): Parkinson's disease; (pha-Syn): phospho-S129 human a-synuclein; (PSA-NCAM): polysialic 
acid-neuronal cell adhesion molecule; (ROI): region of interest; (TH): tyrosine hydroxylase.

\section{Competing interests}

DA, DH, JN, SF, RR, MW and BHP are employees of QPS Austria GmbH.

\section{Authors' contributions}

Conceived and designed the experiments: JN, RR, HR, MW, BHP. Performed the experiments: DA, JN, RR. Analyzed the data: DA, DH, JN, RR. Contributed reagents/materials/analysis tools: ER, EM. Wrote the paper: SF, JN, EM, BHP. All authors read and approved the final manuscript.

\section{Acknowledgements}

We thank Stefan Duller for his support in planning biochemical experiments and Martina Mitrovic for planning behavioral tests. We also like to thank Andres Buonanno of the NIH for providing the C-ErbB4 antibody. This work was supported by R\&D grants of QPS Austria $\mathrm{GmbH}$, and by NIH grants AG18440 and AG022074 (EM).

\section{Author details}

${ }^{1}$ QPS Austria GmbH, Parkring 12, Grambach 8074, Austria. ${ }^{2}$ Karl Franzens University, Institute of Zoology, Graz 8010, Austria. ${ }^{3}$ Department of Pathology, University of California San Diego, La Jolla, CA, USA.

Received: 10 July 2012 Accepted: 3 January 2013

Published: 9 January 2013

\section{References}

1. Goedert M: Parkinson's disease and other alpha-synucleinopathies. Clin Chem Lab Med 2001, 39:308-312.

2. Ibanez P, Bonnet AM, Debarges B, Lohmann E, Tison F, Pollak P, Agid $Y$, Durr A, Brice A: Causal relation between alpha-synuclein gene duplication and familial Parkinson's disease. Lancet 2004, 364:1169-1171.

3. Chartier-Harlin MC, Kachergus J, Roumier C, Mouroux V, Douay X, Lincoln S, Levecque C, Larvor L, Andrieux J, Hulihan M, et al: Alpha-synuclein locus duplication as a cause of familial Parkinson's disease. Lancet 2004, 364:1167-1169.

4. Singleton AB, Farrer M, Johnson J, Singleton A, Hague S, Kachergus J, Hulihan M, Peuralinna T, Dutra A, Nussbaum R, et al: alpha-Synuclein locus triplication causes Parkinson's disease. Science 2003, 302:841.

5. Masliah E, Rockenstein E, Veinbergs I, Mallory M, Hashimoto M, Takeda A, Sagara Y, Sisk A, Mucke L: Dopaminergic loss and inclusion body formation in alpha-synuclein mice: implications for neurodegenerative disorders. Science 2000,

287:1265-1269.

6. Rockenstein E, Mallory M, Hashimoto M, Song D, Shults CW, Lang I, Masliah E: Differential neuropathological alterations in transgenic mice expressing alpha-synuclein from the platelet-derived growth factor and Thy-1 promoters. J Neurosci Res 2002, 68:568-578.

7. Hashimoto M, Rockenstein E, Masliah E: Transgenic models of alpha-synuclein pathology: past, present, and future. Ann N Y Acad Sci 2003, 991:171-188.

8. Shults CW, Rockenstein E, Crews L, Adame A, Mante M, Larrea G, Hashimoto M, Song D, Iwatsubo T, Tsuboi K, et al: Neurological and neurodegenerative alterations in a transgenic mouse model expressing human alpha-synuclein under oligodendrocyte promoter: implications for multiple system atrophy. J Neurosci 2005, 25:10689-10699.

9. Yamakado H, Moriwaki Y, Yamasaki N, Miyakawa T, Kurisu J, Uemura K, Inoue H, Takahashi M, Takahashi R: alpha-Synuclein BAC transgenic mice as a model for Parkinson's disease manifested decreased anxiety-like behavior and hyperlocomotion. Neurosci Res 2012, 73:173-177.

10. Rieker C, Dev KK, Lehnhoff K, Barbieri S, Ksiazek I, Kauffmann S, Danner S, Schell H, Boden C, Ruegg MA, et al: Neuropathology in mice expressing mouse alpha-synuclein. PLoS One 2011, 6:e24834.

11. Nuber S, Petrasch-Parwez E, Winner B, Winkler J, von Horsten S, Schmidt T, Boy J, Kuhn M, Nguyen HP, Teismann P, et al: Neurodegeneration and motor dysfunction in a conditional model of Parkinson's disease. $J$ Neurosci 2008, 28:2471-2484.
12. Richfield EK, Thiruchelvam MJ, Cory-Slechta DA, Wuertzer C, Gainetdinov RR, Caron MG, Di Monte DA, Federoff HJ: Behavioral and neurochemical effects of wild-type and mutated human alpha-synuclein in transgenic mice. Exp Neurol 2002, 175:35-48.

13. Morris R: Thy-1 in developing nervous tissue. Dev Neurosci 1985, 7:133-160.

14. Crews L, Spencer B, Desplats P, Patrick C, Paulino A, Rockenstein E, Hansen L, Adame A, Galasko D, Masliah E: Selective molecular alterations in the autophagy pathway in patients with Lewy body disease and in models of alpha-synucleinopathy. PLOS One 2010, 5:e9313.

15. Price $D L$, Rockenstein $E$, Ubhi K, Phung V, MacLean-Lewis N, Askay D, Cartier A, Spencer B, Patrick C, Desplats P, et al: Alterations in mGluR5 expression and signaling in Lewy body disease and in transgenic models of alpha-synucleinopathy-implications for excitotoxicity. PLoS One 2010, 5:e14020.

16. Dufty BM, Warner LR, Hou ST, Jiang SX, Gomez-Isla T, Leenhouts KM, Oxford JT, Feany MB, Masliah E, Rohn TT: Calpain-cleavage of alpha-synuclein: connecting proteolytic processing to disease-linked aggregation. Am J Pathol 2007, 170:1725-1738.

17. Spencer B, Potkar R, Trejo M, Rockenstein E, Patrick C, Gindi R, Adame A, Wyss-Coray T, Masliah E: Beclin 1 gene transfer activates autophagy and ameliorates the neurodegenerative pathology in alpha-synuclein models of Parkinson's and Lewy body diseases. J Neurosci 2009, 29:13578-13588.

18. Spencer B, Michael S, Shen J, Kosberg K, Rockenstein E, Patrick C, Adame A, Masliah E: Lentivirus Mediated Delivery of Neurosin Promotes Clearance of Wild-type alpha-Synuclein and Reduces the Pathology in an alpha-Synuclein Model of LBD. Mol Ther 2012, .

19. Yacoubian TA, Slone SR, Harrington AJ, Hamamichi S, Schieltz JM, Caldwell KA, Caldwell GA, Standaert DG: Differential neuroprotective effects of 14-3-3 proteins in models of Parkinson's disease. Cell Death Dis 2010, 1:e2

20. Clark J, Clore EL, Zheng K, Adame A, Masliah E, Simon DK: Oral $\mathrm{N}$-acetyl-cysteine attenuates loss of dopaminergic terminals in alphasynuclein overexpressing mice. PLoS One 2010, 5:e12333.

21. Koob AO, Ubhi K, Paulsson JF, Kelly J, Rockenstein E, Mante M, Adame A, Masliah E: Lovastatin ameliorates alpha-synuclein accumulation and oxidation in transgenic mouse models of alphasynucleinopathies. Exp Neurol 2010, 221:267-274.

22. Masliah E, Rockenstein E, Mante M, Crews L, Spencer B, Adame A, Patrick C, Trejo M, Ubhi K, Rohn T, et al: Passive immunization reduces behavioral and neuropathological deficits in an alpha-synuclein transgenic model of Lewy body disease. PLoS One 2011, 6:e19338.

23. Abeliovich A, Schmitz Y, Farinas I, Choi-Lundberg D, Ho WH, Castillo PE, Shinsky N, Verdugo JM, Armanini M, Ryan A, et al: Mice lacking alphasynuclein display functional deficits in the nigrostriatal dopamine system. Neuron 2000, 25:239-252.

24. Maroteaux L, Campanelli JT, Scheller RH: Synuclein: a neuron-specific protein localized to the nucleus and presynaptic nerve terminal. J Neurosci 1988, 8:2804-2815.

25. Anderson JP, Walker DE, Goldstein JM, de Laat R, Banducci K, Caccavello RJ, Barbour R, Huang J, Kling K, Lee M, et al: Phosphorylation of Ser-129 is the dominant pathological modification of alpha-synuclein in familial and sporadic Lewy body disease. J Biol Chem 2006, 281:29739-29752.

26. Chen L, Feany MB: Alpha-synuclein phosphorylation controls neurotoxicity and inclusion formation in a Drosophila model of Parkinson disease. Nat Neurosci 2005, 8:657-663.

27. Paleologou KE, Oueslati A, Shakked G, Rospigliosi CC, Kim HY, Lamberto GR, Fernandez CO, Schmid A, Chegini F, Gai WP, et al: Phosphorylation at $\mathbf{S 8 7}$ is enhanced in synucleinopathies, inhibits alpha-synuclein oligomerization, and influences synuclein-membrane interactions. J Neurosci 2010, 30:3184-3198.

28. Jinno S, Aika Y, Fukuda T, Kosaka T: Quantitative analysis of GABAergic neurons in the mouse hippocampus, with optical disector using confocal laser scanning microscope. Brain Res 1998, 814:55-70.

29. Neddens J, Fish KN, Tricoire L, Vullhorst D, Shamir A, Chung W, Lewis DA, McBain CJ, Buonanno A: Conserved interneuron-specific ErbB4 expression in frontal cortex of rodents, monkeys, and humans: implications for schizophrenia. Biol Psychiatry 2011, 70:636-645. 
30. Neddens J, Buonanno A: Selective populations of hippocampal interneurons express ErbB4 and their number and distribution is altered in ErbB4 knockout mice. Hippocampus 2010, 20:724-744.

31. Vullhorst D, Neddens J, Karavanova I, Tricoire L, Petralia RS, McBain CJ, Buonanno A: Selective expression of ErbB4 in interneurons, but not pyramidal cells, of the rodent hippocampus. J Neurosci 2009, 29:12255-12264.

32. Anton ES, Ghashghaei HT, Weber JL, McCann C, Fischer TM, Cheung ID, Gassmann M, Messing A, Klein R, Schwab MH, et al: Receptor tyrosine kinase ErbB4 modulates neuroblast migration and placement in the adult forebrain. Nat Neurosci 2004, 7:1319-1328.

33. Flames N, Long JE, Garratt AN, Fischer TM, Gassmann M, Birchmeier C, Lai C, Rubenstein $J$, Marin $O$ : Short- and long-range attraction of cortical GABAergic interneurons by neuregulin-1. Neuron 2004, 44:251-261.

34. Ghashghaei HT, Weber J, Pevny L, Schmid R, Schwab MH, Lloyd KC, Eisenstat DD, Lai C, Anton ES: The role of neuregulin-ErbB4 interactions on the proliferation and organization of cells in the subventricular zone. Proc Natl Acad Sci USA 2006, 103:1930-1935.

35. Magavi SS, Leavitt BR, Macklis JD: Induction of neurogenesis in the neocortex of adult mice. Nature 2000, 405:951-955.

36. Okamoto M, Hojo $Y$, Inoue $K$, Matsui $T$, Kawato $S$, McEwen BS, Soya H: Mild exercise increases dihydrotestosterone in hippocampus providing evidence for androgenic mediation of neurogenesis. Proc Natl Acad Sci USA 2012, 109:13100-13105.

37. Ubhi K, Rockenstein E, Mante M, Inglis C, Adame A, Patrick C, Whitney K, Masliah E: Neurodegeneration in a transgenic mouse model of multiple system atrophy is associated with altered expression of oligodendroglial-derived neurotrophic factors. J Neurosci 2010, 30:6236-6246.

38. Scalzo P, Kummer A, Bretas TL, Cardoso F, Teixeira AL: Serum levels of brain-derived neurotrophic factor correlate with motor impairment in Parkinson's disease. J Neurol 2010, 257:540-545.

39. Haaxma CA, Bloem BR, Borm GF, Oyen WJ, Leenders KL, Eshuis S, Booij J, Dluzen DE, Horstink MW: Gender differences in Parkinson's disease. J Neurol Neurosurg Psychiatry 2007, 78:819-824.

40. Deacon RM, Croucher A, Rawlins JN: Hippocampal cytotoxic lesion effects on species-typical behaviours in mice. Behav Brain Res 2002, 132:203-213.

41. Szczypka MS, Kwok K, Brot MD, Marck BT, Matsumoto AM, Donahue BA, Palmiter RD: Dopamine production in the caudate putamen restores feeding in dopamine-deficient mice. Neuron 2001, 30:819-828.

42. Gaffori O, Le Moal M: Disruption of maternal behavior and appearance of cannibalism after ventral mesencephalic tegmentum lesions. Physiol Behav 1979, 23:317-323.

43. Nelson EE, Panksepp J: Brain substrates of infant-mother attachment: contributions of opioids, oxytocin, and norepinephrine. Neurosci Biobehav Rev 1998, 22:437-452.

44. Sandyk R, lacono RP, Bamford CR: The hypothalamus in Parkinson disease. Ital J Neurol Sci 1987, 8:227-234.

45. Rinne UK, Rinne JK, Rinne JO, Laakso K, Tenovuo O, Lonnberg P, Koskinen V: Brain enkephalin receptors in Parkinson's disease. J Neural Transm Suppl 1983, 19:163-171.

46. Klucken J, Poehler AM, Ebrahimi-Fakhari D, Schneider J, Nuber S, Rockenstein E, Schlotzer-Schrehardt U, Hyman BT, McLean PJ, Masliah E, et al: Alpha-synuclein aggregation involves a bafilomycin A 1-sensitive autophagy pathway. Autophagy 2012, 8:754-766.

47. Mak SK, McCormack AL, Langston JW, Kordower JH, Di Monte DA: Decreased alpha-synuclein expression in the aging mouse substantia nigra. Exp Neurol 2009, 220:359-365.

48. Adamczyk A, Solecka J, Strosznajder JB: Expression of alpha-synuclein in different brain parts of adult and aged rats. J Physiol Pharmacol 2005, 56:29-37.

49. Sasahara M, Fries JW, Raines EW, Gown AM, Westrum LE, Frosch MP, Bonthron DT, Ross R, Collins T: PDGF B-chain in neurons of the central nervous system, posterior pituitary, and in a transgenic model. Cell 1991, 64:217-227.

50. Sasahara A, Kott JN, Sasahara M, Raines EW, Ross R, Westrum LE: Platelet-derived growth factor B-chain-like immunoreactivity in the developing and adult rat brain. Brain Res Dev Brain Res 1992, 68:41-53.

51. Neumann M, Kahle PJ, Giasson BI, Ozmen L, Borroni E, Spooren W, Muller V, Odoy S, Fujiwara H, Hasegawa M, et al: Misfolded proteinase K-resistant hyperphosphorylated alpha-synuclein in aged transgenic mice with locomotor deterioration and in human alpha-synucleinopathies. J Clin Invest 2002, 110:1429-1439.

52. Winner B, Rockenstein E, Lie DC, Aigner R, Mante M, Bogdahn U, CouillardDespres S, Masliah E, Winkler J: Mutant alpha-synuclein exacerbates agerelated decrease of neurogenesis. Neurobiol Aging 2008, 29:913-925.

53. Fleming SM, Salcedo J, Fernagut PO, Rockenstein E, Masliah E, Levine MS, Chesselet MF: Early and progressive sensorimotor anomalies in mice overexpressing wild-type human alpha-synuclein. J Neurosci 2004 24:9434-9440.

54. Deacon RM: Assessing nest building in mice. Nat Protoc 2006, 1:1117-1119.

doi:10.1186/1471-2202-14-6

Cite this article as: Amschl et al:: Time course and progression of wild type a-Synuclein accumulation in a transgenic mouse model. BMC Neuroscience 2013 14:6.

\section{Submit your next manuscript to BioMed Central and take full advantage of:}

- Convenient online submission

- Thorough peer review

- No space constraints or color figure charges

- Immediate publication on acceptance

- Inclusion in PubMed, CAS, Scopus and Google Scholar

- Research which is freely available for redistribution 